\title{
Occurrence of selected veterinary pharmaceuticals in water from a fish pond settlement in Ogun state, Nigeria
}

\author{
Olaitan James Olatunde ${ }^{1, *}$, Olukoya Olatunbosun ${ }^{1}$, Ayodele Olatunde ${ }^{1}$, Chimezie Anyakora ${ }^{2}$, \\ Kesi Christopher ${ }^{3}$
}

${ }^{1}$ Department of Pharmaceutical Chemistry, Faculty of Pharmacy, Olabisi Onabanjo University, Sagamu, Ogun State, Nigeria

${ }^{2}$ Department of Pharmaceutical Chemistry, Faculty of Pharmacy, University of Lagos, Lagos State, Nigeria

${ }^{3}$ Department of Pharmaceutical Microbiology, Faculty of Pharmacy, Olabisi Onabanjo University, Sagamu, Ogun State, Nigeria

\section{Email address:}

olatundeolaitan@hotmail.com (O. J. Olaitan)

\section{To cite this article:}

Olaitan James Olatunde, Olukoya Olatunbosun, Ayodele Olatunde, Chimezie Anyakora, Kesi Christopher. Occurrence of Selected Veterinary Pharmaceuticals in Water from a Fish Pond Settlement in Ogun State, Nigeria. International Journal of Environmental Monitoring and Analysis. Vol. 2, No. 4, 2014, pp. 226-230. doi: 10.11648/j.ijema.20140204.16

\begin{abstract}
Pharmaceuticals are emerging contaminants that are increasingly entering the water system. These include veterinary drugs which are used for treating, mitigating or preventing illness or influencing specific body functions in animals. This research is aimed at using HPLC to detect the presence of veterinary drugs that were extracted in fish-pondwastewater and river water from an aqua cultural environment in Ijebu-Ode (Ogun State-Nigeria) using Solid Phase Extraction Cartridges $\left(\mathrm{C}_{8}\right.$ and $\left.\mathrm{C}_{18}\right)$. The three pharmaceuticals tested were Oxytetracycline, Tetracycline and Chloramphenicol. All the pharmaceuticals, except Tetracycline, were found in varying concentrations with the highest value for Chloramphenicol found to be $0.60 \mathrm{ng} / \mathrm{ml}$ and that of Oxytetracycline was $0.46 \mathrm{ng} / \mathrm{ml}$. The discovery of Chloramphenicol and Oxytetracycline in water using SPE-HPLC is novel in Nigeria. This result showed the prevalence of pharmaceuticals in water in this small community which occasionally depends on river water for domestic purposes. Establishing modern wastewater treatment devices which can conveniently remove pharmaceuticals in water before they are discharge into the environment is recommended as this will help to preserve our ecosystem.
\end{abstract}

Keywords: Pharmaceuticals, Ijebu-Ode, Antibiotics, Solid-Phase-Extraction, HPLC, Fish-Pond, Wastewater, Treatment-Plants

\section{Introduction}

Pharmaceuticals are chemicals designed to help improve on the health system of people and animals. But their continual presence in water, soil and the environment generally can threaten the ecosystem. Pharmaceuticals in the environment are often discussed separately as novel or unique environmental contaminants. In fact, pharmaceuticals are just one class of an increasing number of chemicals, referred to here as chemicals of emerging environmental concern or emerging contaminants, which are entering the environment through human and animal waste pathways ${ }^{1,2}$. It is important to consider these emerging contaminants together for two notable reasons. First, they have been found to enter the environment via similar waste pathways and co-occur as mixtures in sensitive environmental settings. Second, they may develop synergistic, antagonistic, or additive interactions that make assessing their potential health effects inextricable ${ }^{3}$. Even though pharmaceuticals are resolutely designed to have a biological effect at prescribed doses, the potential exists for unexpected impact at low concentrations ${ }^{4,5,6}$.

Veterinary medicinal products are intended for use in treating, mitigating, or preventing illness or to influence specific body functions in animals. They are commonly administered to animals for disease control and sometimes added into feeds at subtherapeutic levels to improve feeding efficiency. As a result of these practises, considerable amounts of these medicinal products enter the environment via animal excrements, livestock manure, waste water, and other farm waste especially from intensive fattening operations. Examples of veterinary products include; Carbadox, Aprolium, Momensim and Tylosin ${ }^{7,8,9}$.

People are alarmed by the growing contamination of 
surface and ground water, soil, and food with pharmaceutical residues. It is apparent that measures are needed to enhance the protection of the environment from the adverse effects of pharmaceutical pollution on various levels - from preventive measures on farm level, to the introduction of binding limits for active pharmaceutical ingredients in groundwater and in surface water, to more environmental protection in pharmaceutical approval and regulations for use 9 .

The aim of this study is to screen three selected aqua cultural veterinary pharmaceuticals in surface water in a fish pond community in Ijebu Ode Area of Ogun State, Nigeria, using HPLC Analysis of Solid Phase Extraction techniques. The selected pharmaceuticals are antibiotics. They are Tetracycline, Oxytetraycline and Chloramphenicol. They are employed for the nurturing of fingerlings until they mature. The antibiotics prevent or control all sorts of infections that may kill the fish thereby reducing their yield and market value. Outbreak of American/European foulbrood and breathing disorders in livestock can be prevented using the antibiotics.

\section{Methodology}

\subsection{Chemicals}

All chemical and reagents were of analytical grade and of highest purity possible and were obtained from Fischer Scientific UK. They include Methanol HPLC Grade, Acetonitrile HPLC Grade, Phosphate buffer, Triflouroacetic Acid (TFA) HPLC Grade. Standard Tetracycline (BP), Chloramphenicol (BP) and Oxytetracycline (BP) were supplied by Sigma-Aldrich (Steinheim, Germany). Solid Phase Extraction Cartridges (C18, Si-Cyano and C8) were purchased from SiliCycleInc, Quebec, Canada.<smiles>O=C(N[C@@H](CO)[C@H](O)c1ccc([N+](=O)[O-])cc1)C(Cl)Cl</smiles>

CHLORAMPHENICOL<smiles>CN(C)C1C(O)=C(C(N)=O)C(=O)C2C(O)=C3C(=O)c4c(O)cccc4C(C)(O)C3CC21</smiles>

TETRACYCLINE<smiles>CN(C)C1C(O)=C(C(N)O)C(=O)C2(O)C(=O)C3=C(O)c4c(O)cccc4[C@@H](O)[C@@]3(I)[C@@H](O)[C@]12C</smiles>

OXYTETRACYCLINE

Table 1. Properties Of The Pharmaceuticals

\begin{tabular}{|c|c|c|c|}
\hline Parameters & Chloramphenicol & Tetracycline & Oxytetracylcine \\
\hline IUPAC & $\begin{array}{l}\text { 2,2-dichloro-N-[1,3- } \\
\text { dihydroxy-1-(4- } \\
\text { nitrophenyl)propan-2-yl] } \\
\text { acetamide }\end{array}$ & $\begin{array}{l}\text { (4S,6S,12aS)-4-(dimethylamino)- } \\
\text { 1,4,4a,5,5a,6,11,12a-octahydro- } \\
\text { 3,6,10,12,12a-pentahydroxy-6-methyl- } \\
\text { 1,11-dioxonaphthacene-2-carboxamide }\end{array}$ & $\begin{array}{l}(4 S, 4 \mathrm{a} R, 5 S, 5 \mathrm{a} R, 6 S, 12 \mathrm{a} S) \text {-4-(dimethyl- } \\
\text { amino)-3,5,6,10,11,12a-hexahy-droxy -6- } \\
\text { methyl-1,12-dioxo-1,4,4a, 5,5a,6, 12,12a- } \\
\text { octahydrotetracene-2-carboxa mi de }\end{array}$ \\
\hline FORMULA & $\mathrm{C}_{11} \mathrm{H}_{12} \mathrm{Cl}_{2} \mathrm{~N}_{2} \mathrm{O}_{5}$ & $\mathrm{C}_{22} \mathrm{H}_{24} \mathrm{~N}_{2} \mathrm{O}_{8}$ & $\mathrm{C}_{22} \mathrm{H}_{24} \mathrm{~N}_{2} \mathrm{O}_{9}$ \\
\hline MOLAR MASS & $323.1320 \mathrm{~g} / \mathrm{mol}$ & $444.435 \mathrm{~g} / \mathrm{mol}$ & $460.434 \mathrm{~g} / \mathrm{mol}$ \\
\hline CLASS OF DRUG & Antibiotic & Antibiotic & Antibiotic \\
\hline METABOLISM & Hepatic & Not Metabolized & Not Metabolized \\
\hline BIOAVAILABILITY & $75-90 \%$ & $75 \%$ & $70-77 \%$ \\
\hline HALF LIFE & 1.6-3.3 hour & 8-11 hour & 6-8 hours \\
\hline $\mathrm{H}_{2} \mathrm{O}$ SOLUBILITY & Insoluble in water & Soluble in water & Soluble in water \\
\hline $\mathrm{pKa}$ & 7.47 & 3.30 & 3.27 \\
\hline
\end{tabular}

Drugbank.com

\subsection{Sample Collection}

Water samples were collected in triplicate from four different locations. They include 2 community rivers in Iwata and 2 fish pond wastewater discharge area in Eriwe farm settlement, all in Ijebu Ode area of Ogun State, Nigeria respectively. The sampling was carried-out on the 10th of November, 2013 using coherent protocols and procedures designed to obtain a representative water sample using standard depth and width integrating techniques ${ }^{11}$. At each site of collection, composite water sample was collected from approximately 4 to 6 vertical profiles through a stream cross section. This composite sample was subsequently collected into pre-cleaned amber glass-bottles. These amber glass-bottles were placed in coolers, chilled and maintained at $4^{0} \mathrm{C}$ and then shipped to the laboratory for analysis and were all tested for the presence of the 3 pharmaceutical veterinary compounds. Samples were analyzed within 36 hours of collection. To minimize contamination of samples, use of personal care items (i.e. insect repellents, colognes, and perfumes), 
caffeinated products, pharmaceuticals and tobacco were discouraged during sample collection and processing. This method was a Kolpin et al improved method ${ }^{12}$.

Samples were designated as Sample A, B C and D as specified below:

SAMPLE A - Water from Community River at Iwata, Ijebu-ode; Axis 1.

SAMPLE B - Water from Community River at Iwata, Ijebu-ode; Axis 2.

SAMPLE C - Wastewater from fish pond discharge point at Eriwe farm settlement, Ijebu Ode.

SAMPLE D - Wastewater from fish pond, at Eriwe farm settlement, Ijebu Ode.

\subsection{Sample Preparation}

Each of the water samples collected was subjected to a pre-filtration process by passing the sample through a 0.45 ųm glass fiber filter. The filtrates were respectively collected into a clean container. To further minimize contamination of samples, use of personal care items (i.e. insect repellents, colognes, perfumes), caffeinated products, pharmaceuticals and tobacco were avoided during this process.

\subsection{Solid Phase Extraction}

The pre-concentration of the filtered water samples was achieved using the four Solid-Phase-Extraction (SPE) techniques, namely Conditioning, Loading of Water Sample, Washing and Elution.

- Conditioning: The $2 \mathrm{~g}$ sorbents in each of the $12 \mathrm{ml}$ SPE cartridges were conditioned using $5 \mathrm{mls}$ of water and $5 \mathrm{mls}$ of $10 \%$ methanol

- Loading of Water Sample: $500 \mathrm{ml}$ of the each filtered water samples were respectively loaded into their respective cartridges

- Washing: $10 \mathrm{mls}$ of $10 \%$ methanol was used as the wash solvent

- Elution: $5 \mathrm{mls}$ of $100 \%$ methanol was poured into the cartridge

Multiple samples were processed simultaneously on a 12 well SPE-manifold equipped with a vacuum port. The Vacuum port speeds up the extraction process by pulling the liquid sample through the stationary phase. The analytes were eluted into sample tubes below the manifold after they pass through the stationary phase. The two cartridges used were $\mathrm{C}_{18}$ and $\mathrm{C}_{8}$.

The average volume of eluted samples was $4.3 \mathrm{ml}$. They were made to $5 \mathrm{ml}$ using aqueous high-performance liquid chromatography (HPLC) mobile phase.

\subsection{Preparation of Stock Solution Of Standard}

A $200 \mu \mathrm{g} / \mathrm{ml}$ concentration stock solution was prepared for each of the pharmaceuticals using their respective standards. From the stock solution, $50 \mu \mathrm{g} / \mathrm{ml}, 20 \mathrm{~g} \mu / \mathrm{ml}$, $10 \mu \mathrm{g} / \mathrm{ml}, 5 \mu \mathrm{g} / \mathrm{ml}$ and $1 \mu \mathrm{g} / \mathrm{ml}$ concentrations were also made (according to the specification by the international Conference for harmonization that requires a 5 point calibration curve) using serial dilution.

\subsection{HPLC Analysis}

Analyses of the four extracted compounds were quantitatively carried out using a Reversed Phase Agilent 1100 LC System with UV detector. The analytes were separated with their respective chromatographic conditions stated in Table 2 below.

Table 2. Chromatographic Conditions Of The Three Pharmaceuticals

\begin{tabular}{llll}
\hline Conditions & Tetracycline & Oxytetracycline & Chlorampenicol \\
\hline Stationary Phase & YMC C18 $(100 \times 4.6 \mathrm{~mm}, 5 \mu)$ & YMC C18 $(100 \times 4.6 \mathrm{~mm}, 5 \mu)$ & YMC C18 $(100 \times 4.6 \mathrm{~mm}, 5 \mu)$ \\
Mobile Phase & $50 \mathrm{Mm}$ Phos Buf:ACN $(70: 30)$ & $50 \mathrm{Mm}$ Phos Buf:ACN $(50: 50)$ & $0.1 \%$ TFA:Methanol $(70: 30)$ \\
Flow Rate & $1.0 \mathrm{ml} / \mathrm{minute}$ & $1.5 \mathrm{ml} / \mathrm{minute}$ & $1.0 \mathrm{ml} / \mathrm{minute}$ \\
UV Detector Wavelength & $260 \mathrm{~nm}$ & $250 \mathrm{~nm}$ & $270 \mathrm{~nm}$ \\
Injection Volume & $10 \mu \mathrm{l}$ & $10 \mu \mathrm{l}$ & $10 \mu \mathrm{l}$ \\
Run Time & 2 minute & 2 minutes & 2 minute \\
\hline
\end{tabular}

\section{Result and Discussion}

Calibration curves obtained for the standard concentrations of each of the three pharmaceutical compounds were linear with a correlation coefficient ranging from 0.997-0.999.

The choice of solid phase extraction cartridges used for this research was a function of recovery test conducted. Solid phase extraction cartridges used were those with $\mathrm{C}_{8}$ and $\mathrm{C}_{18}$ sorbents due to their high recovery for the selected pharmaceuticals.

The chromatographic conditions for each of the three antibiotics are presented in table 2. It shows that the analysis of each of the antibiotics were achieved using two different solvents at proportional ratio for the mobile phase namely; 50Mm Phosphate Buffer:Acetonitrile (70:30), 50Mm Phosphate Buffer:Acetonitrile (70:30) and 0.1\% Tatrafluoroacetate:Methanol (70:30) for Tetracycline, Oxytetracycline and Chloramphenicol respectively. The stationary phase used was common to all.

All the water samples analyzed contained two of the tested pharmaceuticals in varying concentrations except sample C. Table 3 gives a summary of the over-all average concentrations of the pharmaceuticals. 
Table 3. Average Concentration Of Drug In Water

\begin{tabular}{llll}
\hline Samples & Chloramphenicol & Oxytetracycline & Tetracycline \\
\hline A & $0.60 \mathrm{ng} / \mathrm{ml}$ & $0.30 \mathrm{ng} / \mathrm{ml}$ & $\mathrm{ND}$ \\
$\mathrm{B}$ & $0.34 \mathrm{ng} / \mathrm{ml}$ & $0.32 \mathrm{ng} / \mathrm{ml}$ & $\mathrm{ND}$ \\
$\mathrm{C}$ & $\mathrm{ND}$ & $\mathrm{ND}$ & $\mathrm{ND}$ \\
$\mathrm{D}$ & $0.42 \mathrm{ng} / \mathrm{ml}$ & $0.46 \mathrm{ng} / \mathrm{ml}$ & $\mathrm{ND}$ \\
\hline
\end{tabular}

The result from this study (table 3) showed the presence of two active veterinary pharmaceuticals (namely Chloramphenicol and Oxytetracycline) in water samples from these communities in very minute quantities of nano-gram. Only sample $\mathrm{C}$ did not contained any of the tested drugs. Tetracycline was also not found in all of the water samples collected. Chloramphenicol has the highest concentration of $0.60 \mathrm{ng} / \mathrm{ml}$ in sample A of the water samples while Oxytetracycline has the lowest concentration of $0.30 \mathrm{ng} / \mathrm{ml}$. Findings from this research supports the facts that Aquacultural bodies are a source through which active pharmaceuticals can be introduced into water cycle, thereby negatively imparting the ecosystem, aquatic organism been the foremost victim. The presence of these pharmaceuticals in water in a community where there are no adequate wastewater treatment plants denies the community an access to pharmaceutical-free water for their domestic use. The presence of these drugs in water constitutes a significant environmental problem that should be addressed by monitoring of these drugs and by implementation of methodologies that contribute to their decrease/elimination from wastewater ${ }^{13}$.

The presence of these drugs in water can be attributed to poor waste-water treatment system in the entire fish pond farming systems in this community. This may be credited to the fact that the farmers are ignorant of the danger of pharmaceuticals in environmental waters since they are still being largely considered as emerging contaminants with little or no immediate side effects. This fact is common to developing countries like Nigeria. Antibiotics are one of the most dangerous drugs to be present in water and the continual presence of these antibiotics in water pose long term threat to human and animal life that depend on untreated water (e.g. river water) for survival in this community. One of such long term effects is resistance of microbial infections to antibiotic therapy. Persistent exposure to Oxytetracycline in water has adverse effect on duckweed $^{14}$. It can also trigger a widespread inflammation process in fish ${ }^{15}$. Ecotoxicity of Chloramphenicol has been indicated in freshwater algae specifically, the growth of algae Chorella pyrenoidosa, Isocrysis albana and Tetraselmis chui ${ }^{16}$. Chen et al also proved the root elongation inhibition potentials of Chloramphenicol indicating some genotoxicity prospectives of long-time exposure to Chloramphenicol in water ${ }^{17}$. Their adverse effect at $\mathrm{mg} / \mathrm{L}$ concentration has also been reported in standard acute aquatic ecotoxicity tests ${ }^{18}$.

This research, which is the Solid-Phase-Extraction and subsequent analysis using HPLC of selected veterinary drugs is novel in Nigeria as there are no available or previous data on occurrence of veterinary pharmaceuticals in Nigeria to relate the outcome of this research too at the time of this publication except for a similar research where the same solid phase extraction method coupled with high performance liquid chromatography were employed to detect some human pharmaceuticals such as Diclofenac, Paracetamol, Chloroquine and Ciprofloxacin in water samples from canal and well in Sango-Ota, Ogun StateNigeria, an industrial city with proximity to Lagos, the commercial city of Nigeria. The pharmaceuticals were discovered in micro-gram $(\mu \mathrm{g})$ quantities ${ }^{19}$.

\section{Conclusion}

To further increase scientific understanding about the potential impacts of these pharmaceuticals in this environment, persistent ecotoxicity studies with more ecologically meaningful endpoints are recommended. Also, to reduce the amount of pharmaceutical waste entering water bodies, preventive measures such as policies promoting/governing disposal practices at concentrated point sources (e.g. health-care and veterinary facilities) is hereby recommended. In addition, takeback programmes, guidance and enhanced consumer education will support efforts for the proper disposal of medicines and reduce the impact of pharmaceuticals entering our water sources.

\section{References}

[1] USEPA. PPCPs and One Approach of EPA/ORD's to "Emerging" Sciences Issues. USEPA National Exposure Research Laboratory Environmental Sciences 2002. /www.epa.gov/esd/chemistry/pharma/science-issues.htm.

[2] U.S. Geological Survey (USGS), Current Analytical Capabilities to Measure Emerging Contaminants in water 2005, : http://toxics.usgs.gov/regiona/emc_water.html, 3 p. (accessed 10/24/05).

[3] Herbert T. Buxton. Pharmaceuticals in the Environment: What we know, and need to know. U.S. Geological Survey, 2008, 609-771-3944.

[4] USEPA. PPCPs and One Approach of EPA/ORD's to "Emerging" Sciences Issues. USEPA National Exposure Research Laboratory Environmental Sciences, 2002b. www.epa.gov/esd/chemistry/pharma/science-issues.htm

[5] Daughton CG, Ternes TA. Pharmaceuticals and Personal Care Products in the Environment: Agents of Subtle Change? Environmental Health Perspectives. 1999, 107:6:907-938

[6] Erickson BE. Analyzing the Ignored Environmental Contaminants. Environmental Science and Technology. 2002, April 1. pp. 140A145A.http://www.epa.gov/esd/chemistry/ppcp/images/estignored-pollutants.pdf.

[7] Song W, Ding Y, Chiou CT, Li H. Selected veterinary pharmaceuticals in agricultural water and soil from land application of animals. J. environ Qual. 2010;39(4):1211-7

[8] PestizidAktions-Netzwerke. V (PAN). Veterinary Medicinal Products and Protection of the Aenvironment. PAN Germany Publishing Publications, 2013, Page 3 
[9] PestizidAktions-Netzwerke. V (PAN). Veterinary Medicinal Products and Protection of the environment. PAN Germany Publications website- www.pan-germany.or/br/projectwork/ veterinary- pharmaceuticals. Retrieved 01-07-2014

[10] DrugBank:http://www.drugbank.ca

[11] Shelton LR. Field guide for collecting and processing stream-water samples for the National Water-Quality Assessment Program.US Geological Survey Open-File Report. 1991, 94-455.

[12] Dana W.Kolpin, Mary Skopec, Michael T.Meyer, Edward T.Furlong,Steven D.Zaugg. Urban contribution of pharmaceuticals and other organic wastewater contaminants to streams during differing flow conditions. Science of the Total Environment 328 (2004) 119-130.

[13] Cavenati S. Simultaneous determination of several veterinary pharmaceuticals in effluents from urban, livestock and slaughterhouse wastewater treatment plants using a simple chromatographic method. Water Sci Technoloy 2012, 66(3):603-11.

[14] Marta Kolodziejska, Joanna Maszkowska, Anna BialkBielinski, Stephanie Steudte, Jolanta Kumirska, Piotr Stepnowski, Stefan Stolte. Aquatic toxicity of four veterinary drugs commonly applied in fish farming and animal husbandry. J. Chemosphere 2013.04.057.
[15] Francisco Barros-Becker, Jaime Romero, Alvaro Pulgar, Carmen G. Feijoo. Persistent oxytetracycline exposure induces an inflammatory process that improves regenerative capacity in Zebrafish Larvae. PLoS ONE 2012, 7(5);e36827.doi;10.1371/Journal.Pone.0036827.

[16] Hong-Thih Lai, Jung-Hsin Hou, Chyong-Ing Su, Chun-Lang Chen. Effects of Chloramphenicol, Florfenicol and Tiampenicol on growth of algae Chorella pyrenoidosa, Isocrysis albana and Tetraselmis chui. Journal of Ecotoxicoloy and Environmental Safety. 2008, 72(2):32934.

[17] Chen QY, Wu ZH, Liu JL. Ecotoxicity of Chloramphenicol and $\mathrm{Hg}$ acting on the root elongation of crops in north china. International Journal of Environmental Research. 2011, 11(5):4:909-916.

[18] Choi K, Kim Y, Jung J, Kim MH, Kim CS, Kim NH, Park J. Occurrence and ecological risks of Roxithromycin, Trimethoprim and Chloramphenicol in the Han River, Korea. Environ Toxicol Chem. 2008 (3):711-9.

[19] Olatunde James Olaitan, Chimezie Anyakora, Tolulope Bamiro and Aminat Temitope Tella. Determination of pharmaceutical compounds in surface and underground water by solid phase extraction-liquid chromatography. Journal of Environmental Chemistry and Ecotoxicology. 2014 Vol. 6(3), pp. 20-26. 